\title{
Manejo da adubação nitrogenada para o milho sob palhada de leguminosas em plantio direto em Gurupi, TO
}

\author{
Nitrogen fertilization management for maize on legume straw crop with no tillage cultivation in Gurupi, \\ Tocantins State
}

\author{
Leonardo Santos Collier ${ }^{1}$ Diôgo Vieira Castro² ${ }^{2}$ Justino José Dias Neto ${ }^{2}$ Domício Rodrigues Brito $^{2}$ \\ Pabblo Atahualpa de Aguiar Ribeiro ${ }^{2}$
}

\section{RESUMO}

O objetivo deste estudo foi avaliar a produção do milho sob níveis de adubação nitrogenada, verificando as alterações na fertilidade do solo e a decomposição de resíduos de crotalária e feijão-de-porco introduzidos em pré-plantio. $O$ experimento foi realizado no ano agrícola 2003/04, no campus universitário de Gurupi-TO, da Fundação Universidade Federal do Tocantins, em um delineamento experimental em blocos aleatórios com parcelas subdivididas em quatro repetições. Nas parcelas foram implantadas Crotalaria juncea (CR) ou feijão-de-porco (Canavalia ensiformis) (FP) e nas subparcelas foram testadas as doses de nitrogênio para a cultura do milho: 0, 50, 100, 150, 200 e $250 \mathrm{~kg} \mathrm{ha}^{-1}$. Independentemente das doses de $N$, verificou-se que os resíduos culturais de CR se decompõem com maior velocidade, quando comparados com os resíduos de FP, contribuindo para a maior produção de milho sob os resíduos de crotalária, devido à maior taxa de decomposição. A maior produtividade de milho foi obtida com $100 \mathrm{~kg} \mathrm{ha}^{-1}$ de $N$ sob palhada de CR, enquanto valor semelhante só foi obtido com $250 \mathrm{~kg} \mathrm{ha}^{-1}$ de $\mathrm{N}$ sob palhada de FP. Após a colheita do milho, observou-se elevação da matéria orgânica do solo sob palha de CR, aumento do $P$ assimilável sob FP e, independentemente da leguminosa, aumento dos teores de Ca, Mg trocáveis.

Palavras-chave: decomposição de resíduos, nitrogênio, plantas de cobertura.

\section{ABSTRACT}

The objective of this research was to evaluate the corn yield on nitrogen fertilizer levels, verifying soil fertility changes and Crotalaria and Canavalia residues decomposition which were cultivated before corn cultivation. The experiment was carried out in 2003/2004 agricultural year in Gurupi Universitary Campus of Federal University of Tocantins, on a split -plot randomized blocks scheme with four repetitions. In plots were cultivated Crotalaria juncea or Canavalia ensiformis, and in split-plots were tested nitrogen level requirements to corn: 0, 50, 100, 150, 200 e $250 \mathrm{~kg} \mathrm{ha}^{-1}$. Independently of $\mathrm{N}$ levels were observed that Crotalaria cultural residues decomposed with higher rate when compared with Canavalia residues, which contributed to better corn grain yield with its residues because higher decomposition rate. The highest corn productivity (9444kg ha-1) was obtained with $100 \mathrm{~kg} \mathrm{ha}^{-1}$ of $\mathrm{N}$ fertilizer with Crotalaria straw residues, while almost the same $\left(9074 \mathrm{~kg} \mathrm{ha}^{-1}\right)$ was only obtained with $250 \mathrm{~kg} \mathrm{ha}^{-1}$ with Canavalia residues. After corn harvesting, there was an increase on organic matter levels on Crotalaria residues, an increase on $P$ levels on Canavalia residues, and with any legume residues, an increase on $\mathrm{Ca}+\mathrm{Mg}$ exchangeable levels.

Key words: residues decomposition, cover crops.

\section{INTRODUÇÃO}

A formação e preservação de coberturas do solo (plantio direto na palha) nas áreas sob cerrado com emprego de materiais de sorgo e principalmente do milheto, já consolidados na região, são opções adotadas em função da versatilidade (produção de grãos, forragem, alta produção de massa para cobertura morta), da rusticidade (pouco exigente em fertilizantes, sistema radicular profundo e abundante, conferindo resistência à seca, às pragas e às doenças), do crescimento rápido e da capacidade de reciclar nutrientes lixiviados (SÉGUY et al., 2001 e BONAMIGO, 1999).

Como alternativa para formação de cobertura de solo, a safrinha (introduzida no fim das chuvas) não vem atingindo suas finalidades principais no Tocantins. Os últimos trabalhos de SILVA et al. (2002) quantificaram alta velocidade de decomposição dos

${ }^{1}$ Curso de Agronomia, Universidade Federal do Tocantins (UFT), Gurupi, TO, Brasil. E-mail: leonardo@uft.edu.br. Autor para correspondência.

${ }^{2}$ Curso de Agronomia, UFT, Gurupi, TO, Brasil. 
resíduos destas culturas, mesmo em períodos de baixa intensidade pluviométrica. Devido ao ciclo da cultura antecessora, os plantios de safrinha não conseguem iniciar antes de meados de março, reduzindo a produção de biomassa devido ao estresse hídrico. O contato deste material sob o solo durante um período superior a 120 dias (até o retorno do período chuvoso) facilita a mineralização dos estoques de carbono do solo (DIEKOW et al., 1997; CASTRO et al., 2004). A possibilidade de exploração das gramíneas de cobertura como forrageiras e produtoras de grãos para alimentação animal ainda é pouco explorada no Estado.

Mesmo que os trabalhos desenvolvidos apresentem benefícios na reciclagem de nutrientes, observados a partir da análise de solo após 18 meses (SILVA et al., 2002), os níveis de matéria orgânica e as produtividades das culturas chegam a decrescer (MONTEIRO, 2001). Uma das estratégias para formação de cobertura foi o plantio da seca ou no pó, que consiste em entrar com o plantio sobre os restos da cultura antecessora, após as primeiras chuvas de setembro (ALTMANN, 2000). Embora espécies como o pé-degalinha, o sorgo e o milheto produzam volume satisfatório de matéria seca, que irá persistir no solo por mais tempo ao receber as culturas tradicionais de milho e soja sob seus resíduos, os estudos indicaram que, mesmo após o cultivo de milho ou soja, os níveis de nutrientes reciclados por esta sucessão de gramíneas não foram capazes de gerar uma economia de fertilizantes satisfatória, principalmente de N e P(SILVA et al., 2002). A perspectiva de economia de fertilizantes nitrogenados pela menor imobilização de N (BASSO \& CERETTA, 2000), aliada à necessidade de diversificação de culturas formadoras de cobertura (RIBEIRO et al., 1999), resulta no uso das leguminosas para formação de cobertura, reduzindo a dependência de maiores doses de $\mathrm{N}$ para o sucesso das culturas sob sistema de plantio direto (SPD) (OLIVEIRA et al., 2002; SÁ, 1996).

Considerando as condições de condução do SPD no sul do Tocantins, o trabalho apresentado teve como objetivo avaliar a produção do milho cultivado no período de safra sob níveis crescentes de adubação nitrogenada, verificando as alterações na fertilidade do solo e acompanhando a decomposição de resíduos de crotalária e feijão-de-porco introduzidos no período de pré-plantio.

\section{MATERIAL E MÉTODOS}

O trabalho foi realizado no campus universitário de Gurupi, na Universidade Federal do Tocantins, localizado a $11^{\circ} 43^{\prime} \mathrm{S}$ e $49^{\circ} 04^{`} \mathrm{~N}$, a $280 \mathrm{~m}$ de altitude, em latossolo vermelho amarelo distrófico. Foi utilizada uma área com histórico de sucessão cultural de gramíneas de cobertura (milheto, sorgo, pé-degalinha e capim Andropogon), cultivada em seguida com milho e soja sob SPD, desde novembro de 2000.

Empregou-se um delineamento experimental em seis subparcelas (de 10,20 $\mathrm{m}^{2}$ cada), com quatro repetições. Nas parcelas, foram plantadas as seguintes espécies para cobertura de solo: (Crotalaria juncea) (CR) e feijão-de-porco (Canavalia ensiformis L.) (FP). Nas subparcelas, foram testadas as seguintes doses de nitrogênio para a cultura do milho: 0, 50, 100, 150, 200 e $250 \mathrm{~kg} \mathrm{ha}^{-1}$.

O solo da área experimental foi amostrado em quatro repetições por parcela ao final da colheita da safra anterior, representando as áreas anteriormente cultivadas com soja (AP cr) e milho (AP fp), ambas na profundidade de $0-15 \mathrm{~cm}$ (Tabela 1$)$. Foi realizada uma calagem utilizando $1,0 \mathrm{mg} \mathrm{ha}^{-1}$ de calcário dolomítico, visando à correção de acidez e ao fornecimento de Ca e Mg para as culturas de CR e FP.

Para o plantio das leguminosas (CR e FP), foi feito um controle químico utilizando Glysphosate 2,5L ha-1 para facilitar o manejo de plantas espontâneas. No dia 12 de outubro, realizou-se o plantio sem adubação química, utilizando espaçamento de $0,35 \mathrm{~m}$ entre linhas para ambas as espécies.

Aos 15 dias após o plantio das leguminosas, foi feito um controle das plantas espontâneas (gramíneas), utilizando fluazofop-p-butil na dose de 2,0L ha-1. Aos 62 dias, período em que as culturas estavam iniciando o florescimento, foram realizadas novas amostragens de solo para análise dos parâmetros químicos da fertilidade, coleta das amostras das plantas para análise da composição química dos resíduos e determinação da quantidade de matéria seca produzida. Em seguida, as culturas foram dessecadas (glifosate 2,0L ha-1e 2,4-D + picloram 0,5L ha-1) e acamadas com o rolo-faca. As amostras de solo utilizaram 4 repetições por leguminosa (APM cr e APM fp), ambas na profundidade de $0-15 \mathrm{~cm}$ (Tabela 1 ).

Após estas operações, foi realizado o plantio do milho híbrido triplo superprecoce AGN 34A11, utilizando $0,45 \mathrm{~m}$ de espaçamento entre linhas e 3,6 plantas por metro linear. A adubação de plantio empregou $120 \mathrm{~kg}$ de $\mathrm{P}_{2} \mathrm{O}_{5}$, utilizando superfosfato simples e $75 \mathrm{~kg}$ de $\mathrm{K}_{2} \mathrm{O}$ (cloreto de potássio), sendo este último aplicado a lanço. Utilizou-se o sulfato de amônio como fonte de nitrogênio, sendo aplicado em plantio $1 / 5$ das doses propostas e o restante parcelado em duas coberturas: a primeira aos 25 dias e a segunda aos 45 dias após o plantio do milho.

A partir do acamamento das plantas de cobertura, iniciou-se o acompanhamento da velocidade de decomposição destes resíduos a cada 30 dias, observando a influência das doses de $\mathrm{N}$ aplicadas. Para esta avaliação, utilizou-se um quadro metálico de área 
Tabela 1 - Resultado dos parâmetros químicos alterados (profundidade de 0-15cm) após o cultivo do milho sob os resíduos de feijão-de porco (fp) e crotalária (cr).

\begin{tabular}{|c|c|c|c|c|c|c|c|c|}
\hline Tratamentos & $\mathrm{Ca}$ & $\mathrm{Mg}$ & $\mathrm{H}+\mathrm{Al}$ & CTC & $\mathrm{K}$ & $\mathrm{P}$ & Mat. org. & $\mathrm{pH}\left(\mathrm{CaCl}_{2}\right)$ \\
\hline & \multicolumn{4}{|c|}{ Mmolc $\mathrm{dm}^{-3}$} & \multicolumn{2}{|c|}{$\mathrm{Mg} \mathrm{dm}^{-3}$} & $\mathrm{G} \mathrm{kg}^{-1}$ & \\
\hline AP fp & 30,0 & 10,0 & 27,0 & 69,7 & 104,7 & 7,0 & 34,0 & 5,4 \\
\hline $\mathrm{AP} \mathrm{cr}$ & 35,0 & 17,0 & 24,0 & 79,7 & 144,0 & 7,8 & 42,0 & 5,8 \\
\hline APM fp & 28,0 & 14,0 & 21,0 & 64,6 & 63,7 & 3,4 & 27,0 & 6,0 \\
\hline $\mathrm{APM} \mathrm{cr}$ & 33,0 & 17,0 & 28,0 & 79,7 & 65,0 & 3,9 & 34,0 & 5,8 \\
\hline DCM fp 0 & 42,3 & 19,0 & 23,3 & 86,8 & 87,0 & 7,5 & 26,7 & 5,8 \\
\hline DCM fp 50 & 40,0 & 17,7 & 27,3 & 87,5 & 99,0 & 10,4 & 28,3 & 5,6 \\
\hline DCM fp 100 & 39,3 & 17,0 & 27,7 & 86,5 & 97,0 & 12,8 & 28,6 & 5,5 \\
\hline DCM fp 150 & 39,0 & 17,0 & 29,0 & 87,3 & 91,0 & 10,7 & 28,0 & 5,4 \\
\hline DCM fp 200 & 40,3 & 17,7 & 27,3 & 87,1 & 70,7 & 12,9 & 27,3 & 5,4 \\
\hline DCM fp 250 & 41,0 & 18,0 & 28,0 & 89,5 & 96,0 & 14,5 & 28,6 & 5,5 \\
\hline DCM cr 0 & 37,3 & 16,3 & 31,7 & 87,7 & 95,3 & 14,8 & 36,0 & 5,3 \\
\hline DCM cr 50 & 38,7 & 17,0 & 30,3 & 88,4 & 91,7 & 9,1 & 35,3 & 5,4 \\
\hline DCM cr 100 & 39,0 & 17,3 & 29,7 & 88,1 & 80,3 & 9,5 & 37,3 & 5,5 \\
\hline DCM cr 150 & 38,7 & 17,3 & 28,7 & 86,5 & 69,7 & 7,5 & 34,6 & 5,6 \\
\hline DCM cr 200 & 37,3 & 16,7 & 30,0 & 85,5 & 58,7 & 9,0 & 34,7 & 5,5 \\
\hline DCM cr 250 & 40,3 & 18,0 & 31,7 & 91,8 & 70,3 & 14,8 & 37,3 & 5,5 \\
\hline CV parcelas & 18,8 & 17,8 & 24 & 20,4 & 36,1 & 66,8 & 38,7 & 6,9 \\
\hline CV subparcelas & 12 & 11,1 & 21,3 & 14,3 & 34,8 & 67,9 & 13,5 & 5,3 \\
\hline
\end{tabular}

AP fp antes do plantio do FP; AP cr antes do plantio da CR; APM fp antes do plantio do milho sob resíduos de FP; APM cr antes do plantio de milho sob resíduos de CR; DCM fp (0, 50, 100, 150, 200, 250) depois do cultivo do milho sob resíduos de FP nas crescentes doses de N; DCM cr $(0,50,100,150,200,250)$ depois do cultivo do milho sob resíduos de CR nas crescentes doses de N.

conhecida $\left(0,0625 \mathrm{~m}^{2}\right)$, que era lançado aleatoriamente dentro das subparcelas, coletando-se a palhada em decomposição. Quatro amostras por subparcela foram secadas na estufa a $75^{\circ} \mathrm{C}$ e posteriormente pesadas, estimando-se assim a redução no peso da palhada (em $\mathrm{kg} \mathrm{ha}^{-1}$ ) a cada 30 dias.

A colheita do milho ocorreu aos 100 dias, com aproximadamente $16 \%$ de umidade dos grãos, utilizando as três linhas centrais de cada parcela. Juntamente com essa operação, foram coletadas amostras de plantas para quantificação da matéria seca produzida nos tratamentos com níveis de N. No final deste período, foram realizadas amostragens do solo, utilizando-se quatro amostras por subparcela (dose de N) para realização de análises químicas de solo, empregando a metodologia da EMBRAPA (1997). As análises estatísticas dos tratamentos entre as doses de nitrogênio e entre as leguminosas empregadas utilizaram o software ESTAT. A produção de grãos e de matéria seca foi submetida ao ajuste de regressão polinomial após ANOVA.

\section{RESULTADOS E DISCUSSÃO}

As produções de matéria seca de CR e do FP foram respectivamente de 9,51 e 6,99mg ha-1. A decomposição inicial dos resíduos culturais é mais intensa quando se elevam as doses de $\mathrm{N}$, para ambos os tipos de resíduos (Figura 1). DIEKOW et al. (1997) e
CERETTA et al. (2002) mostram que as leguminosas apresentam menor relação $\mathrm{C} / \mathrm{N}$ na parte aérea, sendo desta forma um material que se decompõe mais facilmente. Nos primeiros 30 dias após a semeadura do milho, com relação aos resíduos culturais (CR e FP), observou-se que, independentemente da dose de $\mathrm{N}$, a redução no peso da palhada de CR é mais rápida se comparada à do FP (Figura 1$)$.

No tratamento em que não se utilizou $\mathrm{N}$, o peso da palhada do FP em decomposição entre 30 e 60 dias tendeu a se estabilizar, o que provavelmente foi sendo influenciado pelo alargamento da relação $\mathrm{C} / \mathrm{N}$, devido à presença de resíduos de milho cultivado anteriormente. Posteriormente, o peso da palhada do FP começou a cair, o que não ocorreu com os resíduos de $\mathrm{CR}$, que continuaram com a mesma velocidade de decomposição até os 60 dias, tendendo a se estabilizar nas determinações subseqüentes. Acredita-se na influência do nitrogênio disponibilizado pela cultura antecessora (soja), juntamente com um aporte considerável de $\mathrm{N}$ fornecido pela $\mathrm{CR}$, favorecendo uma maior atividade da biomassa microbiana (MOREIRA \& SIQUEIRA, 2002). A velocidade de decomposição de ambas as leguminosas na ausência de $\mathrm{N}$ na adubação deveria ser semelhante, pois os teores de $\mathrm{N}$ encontrados nas plantas de CR e FP foram de 28 e 32,8 $\mathrm{g} \mathrm{kg}^{-1}$, respectivamente. Porém, acredita-se que outros fatores, como a natureza química do resíduo, possam 
influenciar a velocidade de decomposição, pois segundo HOLTZ \& SÁ (1995), devido à estrutura polifenólica muito estável com maiores teores de lignina, a degradação se torna relativamente lenta. Além disso, há variação química conforme espécies, gêneros ou idade da planta, o que pode estar ocorrendo para o FP em relação à CR.

Observa-se que, na ausência da adubação nitrogenada (Figura 2), o rendimento médio de grãos de milho em sucessão à CR é superior em $26 \%$ se comparado com o milho cultivado em sucessão ao FP. Isso pode estar relacionado à quantidade de resíduos e à maior taxa de decomposição inicial de CR (Figura 1), os quais provavelmente fornecem $\mathrm{N}$ em maiores quantidades, na época em que a cultura requer o nutriente em maior abundância.

A produção de milho sob os resíduos de CR (Figura 2) mostrou que houve uma economia de fertilizantes nitrogenados, pois a dose de $100 \mathrm{~kg} \mathrm{ha}^{-1} \mathrm{de}$ $\mathrm{N}$ proporcionou uma produção média de grãos de 9444mg ha-1 ${ }^{-1}$ quando a dose recomendada de $\mathrm{N}$ varia de 120 a 200kg ha-1. Segundo SÁ (1996), a utilização de leguminosa na rotação, antecedendo o milho, proporcionou uma economia de 50\% de nitrogênio, assemelhando-se ao preconizado por SATURNINO
(2001) na mudança do SPD, elevando a produtividade com economia de insumos através de um sistema sustentável.

Em relação à produção de grãos de milho sob os resíduos de FP, pode-se notar que, à medida que se elevam as doses de $\mathrm{N}$, obtém-se um acréscimo na produtividade, não avaliado através de uma relação custo-benefício dos fertilizantes empregados.

Pode-se observar (Figura 2) que a maior produção de matéria seca do milho ocorreu quando cultivado sob resíduos de $\mathrm{CR}$, ao adicionar-se $100 \mathrm{~kg}$ ha $^{-1}$ de $\mathrm{N}$, o que conferiu a maior produtividade de grãos (Figura 2). No geral, a produção de matéria seca em ambas as culturas de cobertura seguiu o mesmo comportamento da produtividade dos grãos. Na situação inicial, a produção de matéria seca superou as quantidades consideradas adequadas por ALVARENGA et al. (2001) para uma boa taxa de cobertura do solo, que é de $6,0 \mathrm{mg} \mathrm{ha}^{-1}$.

Quando se comparam os atributos químicos analisados do início ao final do cultivo do milho sob as duas leguminosas (Tabela 1 ), percebem-se incrementos de até $13 \mathrm{mmol} \mathrm{dm}^{-3}$ de Ca trocável e de $24,9 \mathrm{mmol} \mathrm{dm}^{-3}$ na CTC total, ambos no tratamento com FP. Os teores de Ca e Mg aumentaram após o cultivo do milho,

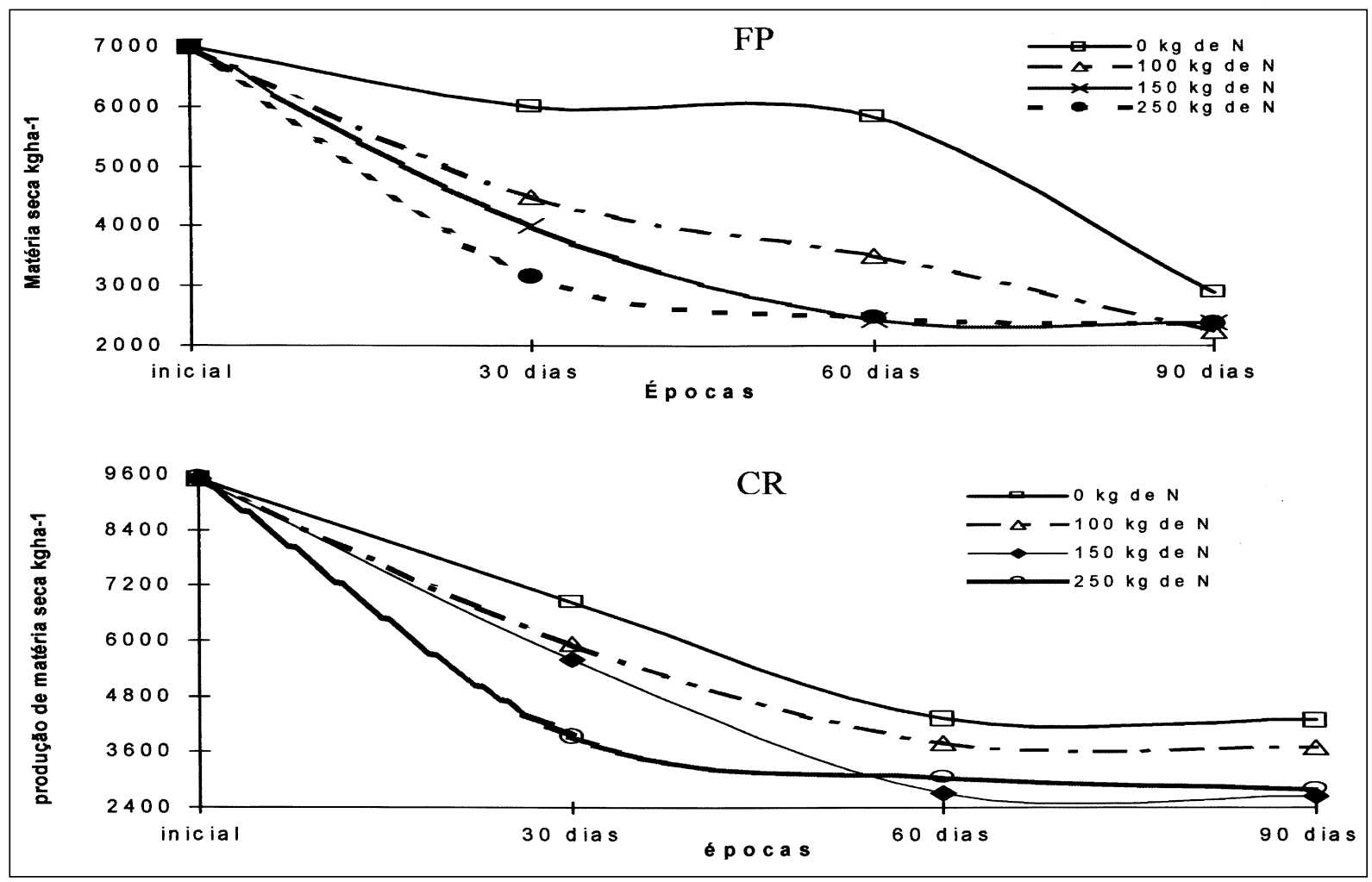

Figura 1 - Reduções de peso da palhada de feijão de porco (FP) e de crotalária, (CR) avaliadas aos 0, 30, 60 e 90 dias após o plantio do milho, Gurupi, 2003/2004. 


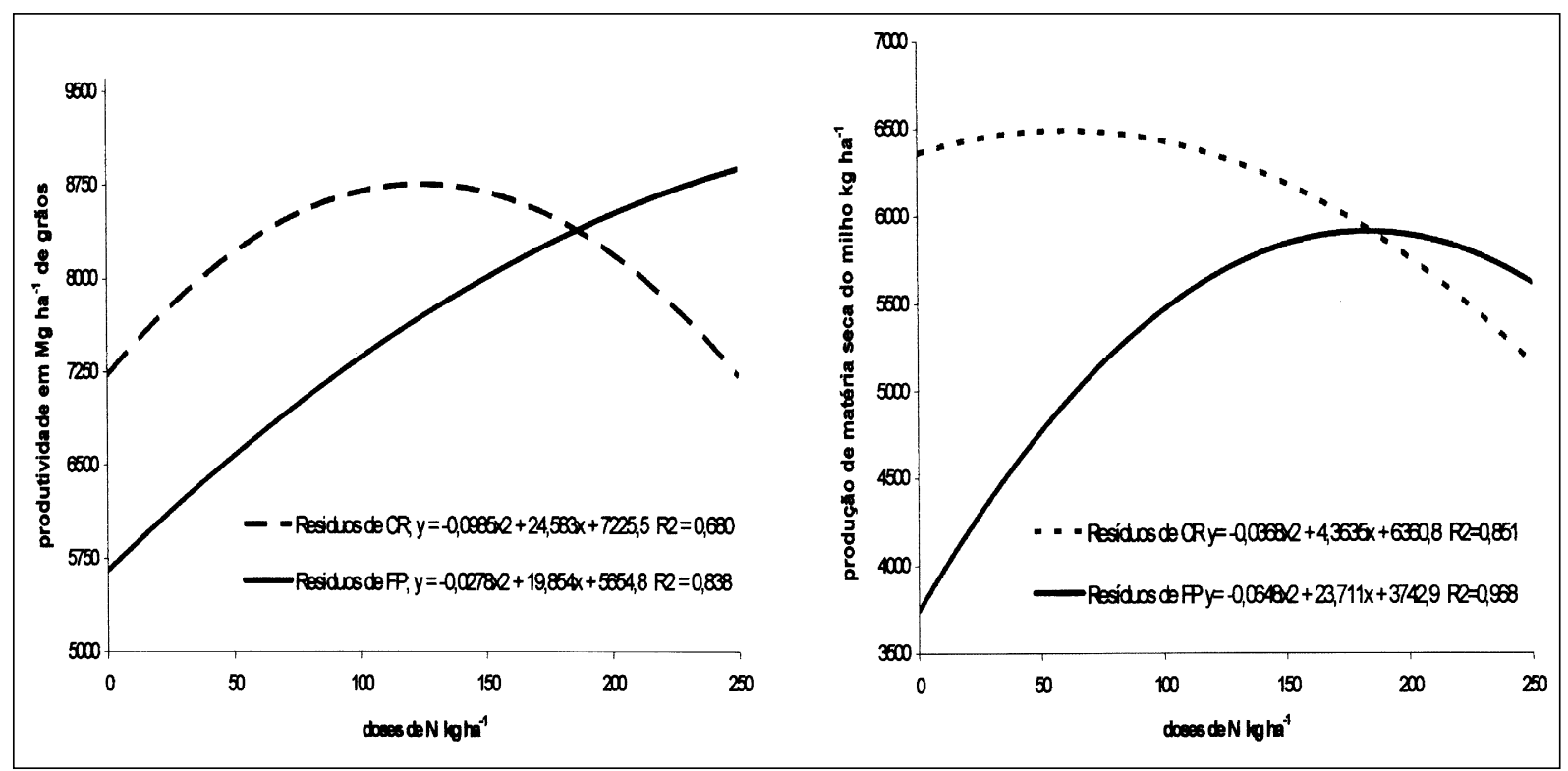

Figura 2 - Produção de grãos e de matéria seca do milho cultivado sob resíduos de CR e FP em doses crescentes de nitrogênio, Gurupi, $2003 / 2004$.

provavelmente devido à contribuição da decomposição dos resíduos das leguminosas anteriormente cultivadas ou da calagem realizada inicialmente. Acredita-se na existência da relação com a redução nos valores de $\mathrm{K}$ inicialmente analisados, pois de acordo com MORAES (1991), o movimento através do solo dos íons $\mathrm{NO}_{3}^{-}, \mathrm{Cl}^{-}$e $\mathrm{SO}_{4}^{-2}$ favorece a lixiviação do $\mathrm{K}$ e de outros cátions presentes na solução do solo e, pelo efeito de valência, estaria ocorrendo preferência para Ca e Mg sobre o K na superfície do solo, facilitando a movimentação do $\mathrm{K}$ para a subsuperfície (ALVARENGA \& LOPES, 1989). Outra hipótese para o decréscimo de Ké a extração deste por meio da planta, sendo exportado pelo grão juntamente com a ausência de adubação potássica de cobertura. COELHO \& FRANÇA (1995) mostram que, para produtividades entre 7,0 - 9,0mg ha-1 , são extraídos de 113 a $143 \mathrm{~kg} \mathrm{ha}^{-1}$ de K. Os incrementos de $\mathrm{K}$ ao final do ciclo, antes que houvesse contato da palha de milho sob o solo, chegam a 35 com o FP e a $30 \mathrm{mg} \mathrm{dm}^{-3}$ com a CR, o que demonstra o potencial de reciclagem de nutrientes dessas leguminosas.

Quando se comparam os atributos químicos do solo após a colheita do milho entre as duas leguminosas, as diferenças entre estas são mais acentuadas para os teores de P, K, e matéria orgânica (Tabela 1), embora não haja diferenças estatísticas entre as duas leguminosas. A maior velocidade de perda de resíduos da CR (Figura 2) devido à decomposição poderia estar liberando $\mathrm{H}^{+}$por parte dos microorganismos através de seus processos naturais, promovendo redução do pH (Tabela 1), o que poderia ter ocorrido quando utilizou-se a CR como cobertura. $\mathrm{O}$ incremento nos teores de $\mathrm{H}+\mathrm{Al}$ de 21,0 para 28,0 com o FP e de 28 para $32 \mathrm{mmol}_{\mathrm{c}} \mathrm{dm}^{-3}$ de solo na CR, ambos no tratamento de maior dose de $\mathrm{N}$, confirma a acidificação sugerida. FREIRE et al. (2001) relatam ainda que é possível, mesmo em SPD, haver áreas com decréscimo de $\mathrm{pH}$ em função de elevadas aplicações de $\mathrm{N}$ na forma $\mathrm{NH}_{4}^{+}$e pela absorção e exportação de bases.

A sucessão (leguminosa/gramínea) não gerou aumentos expressivos nos teores de matéria orgânica até o momento em que foi analisado (Tabela 1); contudo, a CR conseguiu manter níveis mais elevados se comparados aos do FP. Segundo SÁ et al. (2003), a adição de resíduos formados por compostos orgânicos com diferentes estágios de humificação manteria uma decomposição lenta e gradual, restabelecendo o fluxo contínuo de carbono, o qual elevaria os níveis de matéria orgânica do solo em relação ao início do SPD desta área.

Os níveis de $\mathrm{P}$ na camada analisada tiveram acréscimo de até $0,7 \mathrm{mg} \mathrm{dm}^{-3}$ para as duas leguminosas, sendo que no cultivo sob resíduos de CR verificou-se (Tabela 1), menores acréscimos de P quando comparado ao cultivo sob resíduos de FP, exceto para o tratamento com ausência de N. O aumento na participação de formas orgânicas de $\mathrm{P}$ pode estar relacionado aos resultados obtidos na análise de valores inferiores de P assimilável no tratamento com $\mathrm{CR}$, o qual pode não ser sensível pelo extrator empregado em laboratório (OLIVEIRA et al., 2002), como também à extração de $\mathrm{P}$ pelas maiores produtividades da cultura do milho. 


\section{CONCLUSÕES}

Os resíduos culturais de crotalária se decompõem com maior velocidade quando comparados com os resíduos de feijão-de-porco, independentemente das doses de N. Os tratamentos com resíduos de crotalária estão associados a maiores produtividades de grãos, sugerindo uma economia comparativa de fertilizantes nitrogenados. A produtividade de grãos de milho obteve resposta em níveis crescentes de adubação nitrogenada sob os resíduos de feijão-de-porco, enquanto que, na ausência da adubação nitrogenada, o rendimento médio de grãos de milho em sucessão à crotalária é $26 \%$ superior se comparado ao milho cultivado em sucessão ao feijãode-porco.

\section{AGRADECIMENTOS}

Ao Conselho Nacional de Desenvolvimento Científico e Tecnológico (CNPq), pela bolsa do Programa de Iniciação Científica concedida durante o período de realização do trabalho, e à equipe de estudantes colaboradores nos projetos de Ciência do Solo.

\section{REFERÊNCIAS}

ALTMANN, N. Como iniciar em plantio direto (2 ${ }^{\mathrm{a}}$. Parte). In: CABEZAS, W.A.R.L; FREITAS, P.L. (Eds). Plantio direto na integração lavoura-pecuária. Uberlândia: APDC/UFU, 2000. p.217-233.

ALVARENGA, M.I.N.; LOPES, A.S. Influência da adubação potássica no equilíbrio de cátions em Latossolo roxo distrófico, fase cerrado. Pesquisa Agropecuária Brasileira, Brasília, v.23, n.4, p.345-355, 1989.

ALVARENGA, R.C. et al. Plantas de cobertura de solo para sistema plantio direto. Informe Agropecuário, Belo Horizonte, v.22, n.208, p.25-36, 2001.

BASSO, C.J.; CERETTA, C.A. Manejo do nitrogênio no milho em sucessão a plantas de cobertura de solo sob plantio direto. Revista Brasileira de Ciência do Solo, Viçosa, v.24, n.4, p.905-915, 2000.

BONAMIGO, L.A. A cultura do milheto no Brasil, implantação e desenvolvimento no Cerrado, Planaltina, DF, 1998. In: WORKSHOP INTERNACIONAL DE MILHETO, 1998, Planaltina, DF. Anais... Brasília: EMBRAPA Cerrados, 1999. p.31-65.

CASTRO, D.V. et al. Adubação nitrogenada e decomposição de palhada de leguminosas para o milho em plantio direto no Tocantins. 2004. In: REUNIÃO BRASILEIRA DE FERTILIDADE DO SOLO E NUTRIÇÃO DE PLANTAS, 26., 2004, Lages, SC. Anais... Lages: SBCS/UDESC, 2004. 1 CD.

CERETTA, C.A. et al. Produção e decomposição de fitomassa de plantas invernais de cobertura de e milho, sob diferentes manejos da adubação nitrogenada. Ciência Rural, Santa Maria, v.32, p.49-54, 2002.
COELHO, A.M.; FRANÇA, G.E. Seja doutor do seu milho. Informações agronômicas, Piracicaba, n.71, 24p, 1995.

DIEKOW, J. et al. Influência da relação $\mathrm{C} / \mathrm{N}$ de plantas de cobertura do solo e adubação nitrogenada no rendimento de milho. 1997. In: CONGRESSO BRASILEIRO DE CIÊNCIA DO SOLO, 26., 1997, Rio de Janeiro, RJ. Anais... Rio de Janeiro: SBCS/EMBRAPA/UFRRJ, 1997. 1 CD.

EMBRAPA. Manual de métodos de análise de Sso. 2.ed. Rio de Janeiro: CNPS/EMBRAPA/MAA, 1997. 212p.

FREIRE, F. M. et al. Manejo da fertilidade do solo em sistema plantio direto. Informe Agropecuário. Belo Horizonte, v.22, n.208, p.49-62, 2001.

HOLTZ, G.P.; SÁ, J.C.M. Resíduas culturais: reciclagem de nutrientes e impacto na fertilidade do solo. In: CURSO SOBRE MANEJO DO SOLO NO SISTEMA PLANTIO DIRETO, 1995, Passo Fundo. Anais... Passo Fundo: Aldeia Norte, 1994. p.22.

MONTEIRO, F.J.F. Experiências com o plantio direto no cerrado: Gurupi-TO e Balsas-MA. 2001. 42f. Monografia (Curso de Agronomia) - Universidade do Tocantins, Gurupi, Tocantins.

MORAES, J.F.V. Movimento de nutrientes em latossolo vermelho-escuro. Pesquisa Agropecuária Brasileira, v.26, n.1, p.87-97, 1991

MOREIRA, F.M.S.; SIQUEIRA, J.O. Microbiologia e bioquímica do solo. Lavras: UFLA, 2002. 625p.

OLIVEIRA, F.H.T. et al. Fertilidade do solo no sistema plantio direto. In: SBCS. ALVAREZ, V. (Ed.). Tópicos em ciência do solo. Viçosa: Sociedade Brasileira de Ciência do Solo, 2002. V.II, p.393-486

RIBEIRO, A.C. et al. Recomendação de calagem e adubação no sistema plantio direto. In: CFSEMG. Recomendações para o uso de corretivos e fertilizantes em Minas Gerais. Viçosa: Comissão de fertilidade do solo do estado de Minas Gerais, 1999. p.93-98.

SÁ, J.C. de M. Manejo de nitrogênio na cultura de milho no sistema plantio direto. Passo Fundo: Aldeia Norte, 1996. 24p.

SÁ, J.C. et al. Palha: a base de sustentação do plantio direto. Plantio Direto, Passo Fundo, n.74, p.29-32, 2003.

SATURNINO, H.M. Evolução do plantio direto e as perspectivas nos cerrados. Informe Agropecuário, Belo Horizonte, v.22, n.208, p.5-12, 2001.

SÉGUY, L. et al. Sistemas de cultivo e dinâmica de matéria orgânica. Informações Agronômicas. Piracicaba: Potafos, 2001. 32p. (Encarte técnico).

SILVA, F.L. et al. Gramíneas para cobertura em plantio direto no sul do Tocantins: persistência da palha e fertilidade do solo. Cuiabá, MT, 2002. In: REUNIÃO BRASILEIRA DE MANEJO E CONSERVAÇÃO DO SOLO E DA ÁGUA. 14., 2002, Cuiabá, MT. Anais... Cuiabá: SBCS/UFMT, 2002. 1 CD. 